Discussion Paper No. 13-082

Catching the Rebound:

Economy-wide Implications of an Efficiency Shock in the Provision of Transport Services by Households

Simon Koesler

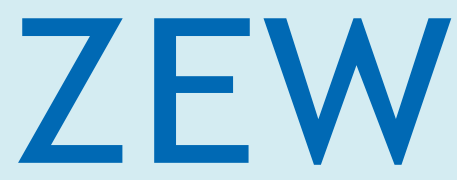

Zentrum für Europäische Wirtschaftsforschung $\mathrm{GmbH}$

Centre for European

Economic Research 


\title{
Discussion Paper No. 13-082 \\ Catching the Rebound: Economy-wide Implications of an Efficiency Shock in the Provision of Transport Services by Households
}

\author{
Simon Koesler
}

Download this ZEW Discussion Paper from our ftp server:

http://ftp.zew.de/pub/zew-docs/dp/dp13082.pdf

Die Discussion Papers dienen einer möglichst schnellen Verbreitung von neueren Forschungsarbeiten des ZEW. Die Beiträge liegen in alleiniger Verantwortung der Autoren und stellen nicht notwendigerweise die Meinung des ZEW dar.

Discussion Papers are intended to make results of ZEW research promptly available to other economists in order to encourage discussion and suggestions for revisions. The authors are solely responsible for the contents which do not necessarily represent the opinion of the ZEW. 


\section{Non-technical Summary}

In this paper, we investigate the rebound effect of an energy efficiency improvement in the provision of private transport services by German households. In the process, we take into account that household behaviour may be influenced by habits, build on a detailed representation of the provision of private transport services, and disentangle the direct and indirect rebound effect. Our analysis shows that rebound has the potential to significantly reduce the expected energy savings of an energy efficiency improvement at households. In particular if households have a flexible demand structure, rebound can erode large parts of efficiency increases. Household habits have an initial detrimental effect on rebound. They limit the ability of households to adapt to changes in the prevailing price and income system and therewith temporally block parts of the channels that lead to rebound. In the long run, however, if habits are formed on the basis of historic consumption, habits do not affect rebound. In isolation, the direct and indirect rebound effect of the efficiency shock are positive, but direct rebound is much stronger.

\section{Das Wichtigste in Kürze}

In diesem Papier untersuchen wir den Rebound-Effekt einer Energieeffizienzverbesserung bei der Bereitstellung von privatem Transport in deutschen Haushalten. Dabei berücksichtigen wir explizit, dass das Konsumverhalten von Haushalten nicht nur von aktuellen Preisen oder Einkommen, sondern potentiell auch von Gewohnheiten bestimmt wird. Unsere Ergebnisse legen nahe, dass der Rebound-Effekt einen signifikanten Teil der erwarteten Energieeinsparung aufzehren kann und so einen Teil des Nutzens einer Effizienzverbesserung verpuffen lässt. Etablierte Konsumgewohnheiten aus der Zeit vor der Effizienzverbesserung können kurzfristig den Rebound-Effekt dämpfen, können ihn langfristig aber nicht reduzieren. Des Weiteren zeigen wir, dass der Direkte-ReboundEffekt (Preis-Effekt) und der Indirekte-Effekt (Einkommens-Effekt) für sich allein genommen positiv sind, der Direkte-Rebound-Effekt ist jedoch deutlich stärker. 


\title{
Catching the Rebound: \\ Economy-wide Implications of an Efficiency Shock in the Provision of Transport Services by Households.
}

\author{
Simon Koesler*
}

October 14, 2013

\begin{abstract}
We investigate the rebound effect of a $10 \%$ energy efficiency improvement in the provision of private transport services by German households. In the process, we take into account that household behaviour may be influenced by habits, build on a detailed representation of the provision of private transport services, and disentangle the direct and indirect rebound effect. Our analysis shows that rebound has the potential to significantly reduce the expected energy savings of an energy efficiency improvement at households. In particular if households have a flexible demand structure, rebound can erode large parts of efficiency increases. Household habits have an initial detrimental effect on rebound. They limit the ability of households to adapt to changes in the prevailing price and income system and therewith temporally block parts of the channels that lead to rebound. In the long run, however, if habits are formed on the basis of historic consumption, habits do not affect rebound. In isolation, the direct and indirect rebound effect of the efficiency shock are positive, but direct rebound is much stronger.
\end{abstract}

Keywords: $\quad$ rebound, efficiency improvement, energy efficiency, habits JEL-Classification: D13, D58, Q41, Q43

\section{Acknowledgments:}

This work has been supported by the German Federal Ministry of Education and Research (BMBF) within the framework of the project "Social Dimensions of the Rebound Effect". For more information on financial support, please visit the website of the author (www.zew.de/staff_sko) and see the annual report of the Centre for European Economic Research (www.zew.de). We gratefully acknowledge helpful comments from Martin Achtnicht and Karen Turner. Of course all remaining errors are ours.

\footnotetext{
${ }^{*}$ Centre for European Economic Research (ZEW Mannheim), L7, 1, 68161 Mannheim, Germany. Email: koesler@zew.de
} 


\section{Introduction}

Efficiency improvements - in particular in the field of energy - are generally seen as one of the major steps towards sustainability. But if consumers and/or firms react to the change in efficiency by adopting their behaviour and choices, the actual benefits of an efficiency improvement can in reality be much lower as originally expected. In the context of energy efficiency improvements, this phenomenon is commonly termed as 'rebound'. It refers to a situation where consumers and firms take advantage of the efficiency improvement and eventually increase their demand for energy (c.f. van den Bergh 2011). A vast stream of literature has emerged discussing this problem. A portfolio of papers on the rebound can, for example, be found in the special issue edited by Schipper (2000). Other articles providing an excellent overview include inter alia Sorrell (2007), Sorrell et al. (2009), van den Bergh (2011) and Turner (2013). Putting a number to the rebound effect is not straightforward and depends crucially, on the context one investigates. As a consequence, a wide range of different rebound estimates exist and presenting a selection would most likely draw a biased picture. Nevertheless, most studies indicate that rebound is not a negligible side effect (e.g. Sorrell 2007, Sorrell et al. 2009, Frondel et al. 2012). Some researchers, however, do argue that the rebound effect is overplayed (e.g. Gillingham

et al. 2013) and only marginally affects the benefits of efficiency improvements, although such critique is quickly rejected by others (e.g. Frondel \& Vance 2013). Some of the controversy around the rebound effect may steam from unclear terminology and a lack of solid analytical foundation in different studies (Turner 2013). Thus, the economic evaluation of the rebound effect should be accompanied by a clear definition of what is under investigation and build on a sound formal foundation.

But the literature on the economy-wide implications of an efficiency shock has so far focused on efficiency improvements on the production side. To our limited knowledge, studies on the economy-wide effects of an efficiency improvement on the household level remain the exception. The paper by Lecca et al. (2013) is such an exception. Inter alia, Lecca et al. provide a clear approach of how to measure rebound both at the economy-wide level as well as on the household level. With this paper, we continue the discussion of the implications of an efficiency improvement at households and investigate the economy-wide effects of an augmented energy efficiency in the provision of private transport services by German households. Thereby, we take into account that, unlike firms, the behaviour of households may be governed by consumer habits. Consumption persistence is an important aspect in this regard, because it will at first limit the potential of households to react to to an efficiency shock and potentially the implications of the efficiency change will only be take place later in time. In this paper, we explicitly focus on an efficiency improvement on the demand side of households and do not consider the possibility that the efficiency improvement itself may trigger additional labour or capital supply by households. Therewith we rule out supply side effects which would lead to general productivity-led growth (c.f. Turner 2013). Moreover, we take up the critique by Turner (2013) and provide a simple but thorough analytical framework on the basis 
of which we can illustrate different effects that overall result in rebound.

On this account, the remainder of this paper is structured as follows. We first give a formal illustration of how rebound can arise in the context of an energy efficiency improvement at households and present different rebound channels on the basis of a small stylised example. Next, we apply the mechanism of the small theoretical model in a more general setting and evaluate the different drivers of the rebound effect on the basis of a computable general equilibrium (CGE) model. Finally, we summarise our results and conclude.

\section{Rebound in the Context of Households}

Most of the literature on the economy-wide rebound effect focusses on efficiency improvements in production sectors. In this paper, we turn our attention to the rebound effect and its channels in the context of households. But before we specifically investigate the implications of a $10 \%$ efficiency shock in the provision of private transport services by German households, we present the different effects that ought to be expected on the basis of a simple illustrative example. Later, we generalise the setup and turn to a more comprehensive setting, which nevertheless incorporates the main mechanisms of the example presented in the following.

The example features one representative household, a set of $n$ services used for final consumption, and $m$ intermediate commodities used by the households to produce the utility-generating services they eventually consume. The distinction between services and commodities is based on the idea that households do rarely actually consume commodities, such as cars and gasoline or light bulbs and electricity, but combine these to form a service they enjoy such as mobility/transport services or light. The potentially rebound-triggering efficiency increase eventually takes place on the level of the provision of the services and makes a specific intermediate input more productive. All agents take prices as given.

\subsection{Household Problem}

Household utility is given by a Cobb-Douglas utility function encompassing $n$ different services. The same mechanisms and conclusion emerge when applying a more general Constant Elasticity of Substitution (CES) utility function. But for the sake of clarity, we limit ourself in this stylised example to a Cobb-Douglas utility function and generalise at a later stage. In our analysis, we include a particularity of the household context, namely habits. We model habits in the spirit of Pollak (1970) and von Weizsäcker (1971) and include a habit formation process in the household problem by extending the standard Cobb-Douglas utility function with a term that can be interpreted as some form of necessary consumption. Necessary consumption results from the consumption level in the previous period and thus relates the current consumption decision to the 
past. Accordingly, household utility at time $t$ is given by:

$$
U_{t}\left(x_{i ; t} ; x_{i ; t-1}\right)=\prod_{i=1}^{n}\left(x_{i ; t}-\theta_{i} x_{i ; t-1}\right)^{\alpha_{i}}, \text { with } \sum_{i=1}^{n} \alpha_{i}=1 .
$$

$x_{i, t}$ gives the amount of service $i$ that is consumed by the household in period $t$ and $\alpha_{i}$ is the corresponding expenditure share. The strength of the persistence of past consumption or, in other words, the strength of the habit formation process is given by $\theta_{i}$ 's. Note that for simplicity we limit the habit formation process to one period. But it is straightforward that extending the range of habits has the same effect as increasing all $\theta_{i}$ s. Households have to obey a budget constraint of the form $M=\sum_{i=1}^{n}\left(p x_{i} x_{i ; t}\right)$. We assume that households have a fix income $M$ which is not influenced by the efficiency change. As described by Turner (2013), this ensures that the efficiency shock will not trigger a productivity-led growth process and allows us to focus on demand side effects. If households take past consumption as given, demand for service $x_{i}$ in period $t$ by households is given by:

$$
x_{i ; t}=\frac{M-\sum_{j=1}^{n}\left(p x_{j} \theta_{j} x_{j ; t-1}\right)}{p x_{i} \sum_{j=1}^{n}\left(\frac{\alpha_{j}}{\alpha_{i}}\right)}+\theta_{i} x_{i ; t-1} .
$$

\subsection{Provision of Services}

The provision of the service $x_{i}$ by households is characterised by a CES function with input-specific efficiency:

$$
x_{i}\left(z_{j}\right)=\left(\sum_{j=1}^{m}\left(\beta_{j ; i}\left(\gamma_{j ; i} z_{j}\right)^{\rho_{i}}\right)\right)^{\frac{1}{\rho_{i}}}
$$

$z_{j}$ are commodities required to produce the service $x_{i}, \gamma_{j ; i}$ the corresponding level of input efficiency which is initially assumed to equal one, $\beta_{j ; i}$ the respective input share and $\rho_{i} \leq 1$ a parameter defining the substitutability between intermediate inputs which is related to the respective elasticity of substitution through $\rho_{i}=\frac{\sigma_{i}-1}{\sigma_{i}}$. Note that for the generation of $x_{i}$ we have omitted the time indices as production always refers to the current period $t$. Note also that in order to be able to focus on the rebound effect, we assume that commodities required to generate the services come from a sufficiently large market and are supplied to households at a demand-independent price of $p z_{j}$. Demand for a commodity $j$ for the generation of service $x_{i}$ is given by:

$$
z_{j ; i}\left(x_{i}\right)=\left(\frac{\gamma_{j ; i}^{\rho_{i}} \beta_{j ; i}}{p z_{j}}\right)^{\frac{1}{1-\rho_{i}}}\left(\sum_{j=1}^{m}\left(\left(\gamma_{j ; i}^{\rho_{i}} \beta_{j ; i}\right)^{\frac{1}{1-\rho_{i}}}\left(p z_{j}\right)^{\frac{\rho_{i}}{\rho_{i}-1}}\right)\right)^{-\frac{1}{\rho_{i}}} x_{i}
$$

Combining Equation 2 with Equation 4 provides the amount of commodity input $z_{j ; t}$ 
that is required to fulfill the demand of the representative household for $x_{i ; t}$ at time $t$ :

$$
\begin{aligned}
f z_{j ; i ; t}= & \underbrace{\left(\frac{\gamma_{j ; i}^{\rho_{i}} \beta_{j ; i}}{p z_{j}}\right)^{\frac{1}{1-\rho_{i}}}\left(\sum_{j=1}^{m}\left(\left(\gamma_{j ; i}^{\rho_{i}} \beta_{j ; i}\right)^{\frac{1}{1-\rho_{i}}}\left(p z_{j}\right)^{\frac{\rho_{i}}{\rho_{i}-1}}\right)\right)^{-\frac{1}{\rho_{i}}}}_{\mathrm{A}} \\
& {[\underbrace{\left(\frac{M-\sum_{l=1}^{n}\left(p x_{l} \theta_{l} x_{l ; t-1}\right)}{p x_{i} \sum_{l=1}^{n}\left(\frac{\alpha_{l}}{\alpha_{i}}\right)}\right)}_{\mathrm{B}}+\underbrace{\theta_{i} x_{i ; t-1}}_{\mathrm{C}}] }
\end{aligned}
$$

$f z_{j ; i ; t}$ can be decomposed in three main elements: the intermediate intensity of a service $A$, the household demand for a service in the current period $B$ and the household demand for a service resulting from the habit formation process $C$.

\subsection{Rebound Effect}

The rebound effect is generally understood as an increase in the use of an intermediate input of a product or service triggered by an amelioration of the input-specific efficiency of the intermediate in question. While in principle rebound is a universal concept and can be applied to any input of a production process, it is mainly studied in the context of energy and environmental policy as it makes the net effect of any increase in energy efficiency ambiguous and may undermine such policies (cf. Sorrell \& Dimitropoulos 2008, van den Bergh 2011). For the sake of generality, we take a broader perspective on the rebound in this section and will only later turn our attention to energy as an input into the production of private transport services. In our small stylised example, the rebound effect boils down to a change in the amount of intermediate commodities $z_{j^{*}}$ employed in the provision of services as a consequence of a change in the efficiency $\gamma_{j^{*}}$.

The rebound effect is frequently divided into three separate effects (e.g. Sorrell \& Dimitropoulos 2008), the direct rebound, the indirect rebound or income effect and the economy-wide rebound effect. Although we acknowledge that such a categorisation of the rebound effect may be limited (Turner 2013), for the illustrative purpose of this section, we adhere to the approach of dividing the rebound effect into the direct, indirect and economy-wide effects.

\subsubsection{Direct Rebound}

The direct rebound effect emerges from the fact that efficiency improvements in the provision of a product or service will lead to a decrease in the effective price of that product or service. Ceteris paribus, this will lead to an increase in the demand for that product or service and thus a higher demand for the intermediates necessary to meet the additional demand. Following others (e.g. Berkhout et al. 2000, Sorrell \& Dimitropoulos 2008), we define the direct rebound effect as the efficiency elasticity of demand for service $\eta_{i^{*} ; t}^{\text {Service }}$ and build on the fact that the efficiency elasticity of demand for the services is 
equal to the efficiency elasticity of demand for the input commodity $\eta_{i^{*} ; t}^{\text {Commodity }}$ plus one $\left(\eta_{i^{*} ; t}^{\text {Service }}=\eta_{j^{*} ; i^{*} ; t}^{\text {Comodity }}+1\right)$. The direct rebound $R_{j^{*} ; i^{*} ; t}^{\text {Direct }}$ with regard to the service $i^{*}$ resulting from an efficiency increase in use of the intermediate commodity $j^{*}$ at time $t$ can thus be computed as:

$$
R_{j^{*} ; i^{*} ; t}^{\text {Direct }}=\eta_{i^{*} ; t}^{\text {Service }}=\eta_{j^{*} ; i^{*} ; t}^{\text {Commodity }}+1=\frac{\partial f z_{j^{*} ; i^{*} ; t}}{\partial \gamma_{j^{*} ; i^{*}}} \frac{\gamma_{j^{*} ; i^{*}}}{f z_{j^{*} ; i^{*} ; t}}+1
$$

The direct rebound originates from each of the three main components of the demand for commodities: the intermediate intensity $A$ and the household demands for the service $B$ and $C$. It can be decomposed to:

$$
\begin{aligned}
R_{j^{*} ; i^{*} ; t}^{\text {Direct }}= & \underbrace{\frac{\partial A}{\partial \gamma_{j^{*} ; i^{*} ; t}}\left(\frac{\gamma_{j^{*} ; i^{*} ; t} B}{A B+A C}+\frac{\gamma_{j^{*} ; i^{*} ; t} C}{A B+A C}\right)}_{\text {input change due to change of input intensity }} \\
& +\underbrace{\frac{\partial B}{\partial \gamma_{j^{*} ; i^{*} ; t}} \frac{\gamma_{j^{*} ; i^{*} ; t}}{B+C}}_{\text {input change due to change in current demand }} \\
& +\underbrace{\frac{\partial C}{\partial \gamma_{j^{*} ; i^{*} ; t}} \frac{\gamma_{j^{*} ; i^{*} ; t}}{B+C}}_{\text {input change due to change in demand due to habit }}
\end{aligned}
$$

The first term is the input change due to change of input intensity, the second is the input change related to a change of current consumption decision and the third term is the input change attributable to the habit formation process.

In contrast to many other studies, we take into account that household demand can feature rigidities and thus the rebound effect can also be expected to depend on how fast household demand changes. In our context, which includes a habit formation process over two periods, the rebound effect is thus time specific and can be expected to vary between the period of the actual efficiency shock and the subsequent periods. The overall direct rebound effect must be evaluated by taking into account the changes of $f z_{j^{*} ; i^{*} ; t}$ over the period of the efficiency change $s$ and all subsequent periods $s+1, s+2, \ldots$ But as we limit ourselves to the direct rebound and for the time being abstract from income and general equilibrium effects, we can focus on the period of the efficiency shock and the period directly afterwards. Accordingly, in the following we will first determine the rebound at period $s$ and then at $s+1$.

Rebound in $\boldsymbol{t}=s$ : Since demand arising from habits is based on the previous period and thus will not instantly react to a efficiency increase in period $s$, or more formally $\frac{\partial C}{\partial \gamma_{j ; s}}=0$, the rebound in $s$ is only driven by the change in input intensity and change in current demand. Thus:

$$
R_{j^{*} ; i^{*} ; s}^{\text {Direct }}=\frac{\partial A}{\partial \gamma_{j^{*} ; i^{*} ; s}}\left(\frac{\gamma_{j^{*} ; i^{*} ; s} B}{A B+A C}+\frac{\gamma_{j^{*} ; i^{*} ; s} C}{A B+A C}\right)+\frac{\partial B}{\partial \gamma_{j^{*} ; i^{*} ; s}} \frac{\gamma_{j^{*} ; i^{*} ; s}}{B+C}
$$

The change in input intensity is governed by the same mechanism as for inputaugmenting / input-biased technical change, which is illustrated in Acemoglu (2002). 
If $\sigma_{i^{*}}<1$, producers of the service find it difficult to substitute in favour of the input experiencing a higher efficiency and the corresponding input intensity falls after the efficiency shock. If, however, input substitutability is rather high and $\sigma_{i^{*}}>1$, producers will take advantage of the efficiency increase by using more of the respective input in relative terms and the input intensity rises. Since $\left(\frac{\gamma_{j^{*} ; i^{*} ; t} B}{A B+A C}+\frac{\gamma_{j^{*} ; i^{*} ; t} C}{A B+A C}\right) \geq 0$ holds for all plausible parameter specifications, this implies that the rebound from an input change associated with a change of input intensity is negative if $\sigma_{i^{*}}<1$, zero if $\sigma_{i^{*}}=0$ (this implies a Cobb-Douglas production function in which input intensities are constant) and positive if $\sigma_{i^{*}}>1$.

With regard to changes in current demand, following the logic that $\frac{\partial p x_{i^{*}}}{\partial \gamma_{j^{*} ; i^{*} ; s}} \leq 0$ must hold as otherwise the efficiency improvement would be discarded, $\frac{\partial B}{\partial \gamma_{j^{*} ; i^{*} ; s}} \geq 0$ and current demand will increase. In combination with the fact that for all possible parameter values $\frac{\gamma_{j^{*} ; i^{*} ; t}}{B+C} \geq 0$, there is a positive rebound arising from a change in current demand.

But due to the ambiguity with regard to the effect arising from the input intensity, the total direct rebound effect in period $s$ remains unclear and depends on the parameterisation of the model, in particular with regard to the definition of $\sigma_{i^{*}}$.

Rebound in $\boldsymbol{t}=s+1$ : Putting any general equilibrium effects aside, in the period following the efficiency shock $s+1$, there are no further adjustments attributable to the change in efficiency with regard to input intensity and current demand or formally $\frac{\partial A}{\partial \gamma_{j^{*} ; i^{*} ; s+1}}=0$ and $\frac{\partial B}{\partial \gamma_{j^{*} ; i^{*} ; s+1}}=0$. Consequently, the direct rebound in period $s+1$ reduces to:

$$
R_{j^{*} ; i^{*} ; s+1}^{\text {Direct }}=\frac{\partial C}{\partial \gamma_{j^{*} ; i^{*} ; s+1}} \frac{\gamma_{j^{*} ; i^{*} ; s+1}}{B+C}
$$

Following the same logic as for the rebound effect arising from additional current demand. The rebound from a change in demand due to the habit of consuming more is positive since $\frac{\gamma_{j^{*} ; i^{*} ; t}}{B+C} \geq 0$ and $\frac{\partial C}{\partial \gamma_{j^{*} ; i^{*} ; s+1}} \geq 0$.

Overall Direct Rebound: Table 1 gives an overview of the different direct rebound channels in this simple illustrative example. As expected, if due to habits, households do not instantaneously adjust their consumption decision in face of a efficiency shock, the direct rebound effect is time dependent. In the period of the efficiency change, only two of the three possible direct rebound channels are active and the effect is reduced compared to a situation without a habit formation process. In the subsequent period, the remaining direct rebound channel is open and can add to the overall effect. Although the other channels are now closed. From a long-run perspective, all direct rebound channels are active and the overall effect is the same as in a situation without demand-side rigidity because of habits. However, given the uncertainty of the direction of the effect from the change in the input intensity, the overall rebound effect remains ambiguous at first. Only in the case of $\sigma_{i^{*}}>1$, we can be sure that in total there is a positive direct rebound from an efficiency improvement. 
Table 1: Overview of direct rebound effects

\begin{tabular}{lll}
\hline Period & Rebound Channel & Effect on Input and Rebound \\
\hline $\mathrm{t}=\mathrm{s}$ & Input intensity & negative if $\sigma_{i^{*}}<1 ;$ \\
& & neutral if $\sigma_{i^{*}}=1 ;$ \\
& positive if $\sigma_{i^{*}}>1$ \\
& Current demand & positive \\
& Demand from habits & neutral \\
\hline $\mathrm{t}=\mathrm{s}+1$ & Input intensity & neutral \\
& Current demand & neutral \\
& Demand from habits & positive \\
\hline overall & Input intensity & negative if $\sigma_{i^{*}}<1 ;$ \\
& & neutral if $\sigma_{i^{*}}=1 ;$ \\
& Current demand & positive if $\sigma_{i^{*}}>1$ \\
& Demand from habits & positive \\
\hline
\end{tabular}

\subsubsection{Indirect Rebound}

The indirect rebound effect or income effect as it is also termed occasionally, builds on the logic that a decrease in the effective price of a product or service resulting from the more efficient provision of the product or service, will also relax the budget constraint of consumers. That is, if not all of the cost savings are used up by the direct rebound. This enables consumers to demand more of other products or services and may again lead to an increase in intermediate demand which can be interpreted as rebound (e.g. Sorrell \& Dimitropoulos 2008). Thereby the amount of intermediates embodied in the additional consumption of other products or services is crucial. For a ceteris paribus analysis it is thereby irrelevant what initially triggered the relaxation of the budget constraint and the demand shock associated to the indirect rebound is thus equivalent to a general income increase experienced by the consumer. Accordingly, we define the indirect rebound effect of an efficiency change in the provision of service $i^{*}$ related to the intermediate input $j^{*}$ as the change in the embodied intermediate $j^{*}$ resulting from a change of the consumption of other services following a general change in the budget $M$ in relation to the expected change in intermediate consumption of $j^{*}$ due to the efficiency gain:

$$
R_{j^{*} ; i^{*} ; t}^{\text {Indirect }}=\frac{\sum_{i=1 ; i \neq i^{*}}^{m}\left(\frac{\partial x_{i ; t}}{\partial M} \frac{M}{x_{i ; t}} \Delta M f z_{j^{*} ; i ; t}\right)}{\left(\Delta \gamma_{j^{*} ; i^{*}}\right) z_{j^{*} ; i^{*} ; t}}
$$

The nominator is based on Equation 5, which ultimately represents the intermediate 
$j$ inputs embodied in service $i$. Note that in our model $\frac{\partial x_{i ; t}}{\partial M} \frac{M}{x_{i ; t}}=1$ as we build on a CES framework for the utility function. The denominator features the amount of intermediates $j^{*}$ that one would expect to be saved in the consequence of the productivity increase on the basis of technical deliberations.

The interpretation of Equation 10 is straightforward. All components of $R_{j^{*} ; i^{*} ; t}^{\text {Indirect }}$ are positive, thus the budget increase leads to an increase in the use of intermediates and opens an additional channel for the rebound effect. Similar to the direct rebound effect and resulting from the consideration of household habits, the indirect effect is time dependent. As $\frac{\partial f z_{j ; i ;}}{\partial \theta_{i}} \geq 0$, habits have an initial depressing effect on the indirect rebound effect, but in the long run consumption persistence has no effect on the indirect rebound.

\subsubsection{Economy-Wide Rebound}

As presented above, a change in the efficiency leads to an adjustment of prices and available income. But so far, we have limited ourself to a ceteris paribus analysis of the efficiency change. In a more general setting, where prices and quantities are free to adjust, the change in prices and demand initiated by the efficiency shock will lead to a series of secondary adjustments of prices and quantities beyond the specific area of efficiency change throughout the economy. An example for such a processes would be an increase in the demand of energy of firms if the efficiency improvement in the provision of private services reduces the demand for energy of households and therewith has a lowering effect on general energy prices. Such adjustments are commonly termed as the economy-wide rebound effect as they may also result in an increase in the demand of intermediates and may counter the benefits of the efficiency change.

Since the consecutive adjustment of all prices and quantities can no longer be illustrated in a meaningful manner, an evaluation of the economy-wide rebound effect is beyond the scope of our stylised example. For such an analysis, a general equilibrium framework is well suited. Accordingly, we now turn to a general equilibrium analysis of the rebound. At this point, we also become more specific with regard to our evaluation of the rebound effect and study the economy-wide implications of an increase in the efficiency of energy in the provision of transport services by households in the presence of consumer habits on the basis of a computable general equilibrium (CGE) analysis.

\section{CGE Analysis}

\subsection{Model}

After having given a comprehensive formal overview of the rebound effect in the context of households, we now explore the rebound effect in a more general setting. On that account, we include the main elements of the stylised example of the previous section in a general equilibrium model. This relates mainly to the utility function with habits and the idea that households are responsible for the provision of certain services such 
as transportation. Admittedly, in order to have a good representation of household behaviour, we implement a somewhat more elaborated nesting structure for household utility and the provision of transport services. Though the mechanisms nevertheless remain the same. We build on a basic version of the WIOD CGE model, which is a static (in the sense that there is no investment decision and a fix factor supply), multiregion, multi-sector CGE model that has been developed in the spirit of the CGE model PACE (cf. Alexeeva-Talebi et al. 2012) but which, instead of GTAP data, relies on data from the World Input-Output Database (WIOD) (Timmer et al. 2012, Dietzenbacher et al. 2013).

The basic CGE model distinguishes between two groups of commodities: energy commodities $Y_{(e g ; r)}$ and non-energy commodities $Y_{(n e g ; r)}$. The production of these goods is characterised by CES functions and constant returns to scale. Nested CES functions with three levels are employed to specify the substitution possibilities between capital $K_{(r)}$, labour $L_{(r)}$, energy inputs $A_{(e g ; r)}$ and non-energy intermediate inputs $A_{(n e g ; r)}$ of sectors. We apply a KLEM production structure, where capital and labour enter the production function on the lowest level, on the second level value added is combined with energy, and finally on the top level of the CES function the energy-value-added composite is combined with a non-energy material aggregate. An overview of the production structure is given in Figure 1. The sectoral output can be used for intermediate use and/or final consumption domestically and/or exported to other regions. Perfect competition is assumed in all markets. The choice among imports and domestically produced commodities is based on Armington's idea of regional product differentiation Armington 1969), id est domestic and foreign commodities are distinguished by origin and are not necessarily perfect substitutes. Each region is represented by a representative household who maximises his utility by purchasing bundles of consumption goods subject to factor and tax income. Originally, utility of households $U_{(r)}$ is also given by a CES function incorporating energy $A_{(e g ; r)}$ and a non-energy Armington bundle $A_{(n e g ; r)}$. Households are endowed with a fixed amount of capital and labour. Thus, as in our stylised example, factor supply and therewith the main income source of households is independent of the efficiency shock and enables us to focus on demand side effects. Capital and labour is mobile across sectors within regions but not across regions. Note, whenever no ambiguity arises with respect to the underlying time period, we omit the $t$ index when we relate variables to the present period $t$.

As we are interested in the effects of a change in the efficiency of the generation of transport services at the households, we extend original structure of household demand in the basic WIOD CGE model with regard to three aspects. First, we extend the basic utility function to feature a distinction between transport services and non-transport consumption. Accordingly, the utility of the representative agent is given by:

$$
U_{(r)}=\left(\alpha_{(r)}^{\mathrm{Utrns}}\left(T R N s_{(r)}^{\text {total }}\right)^{\rho^{\mathrm{Utrnsme}}}+\alpha_{(r)}^{\mathrm{Ume}}\left(M E_{(r)}\right)^{\rho^{\mathrm{Utrnsme}}}\right)^{\frac{1}{\rho^{\mathrm{Utrnsme}}}}
$$




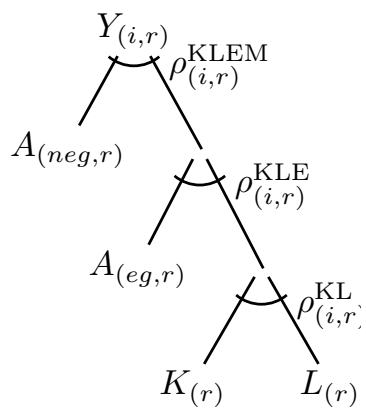

Figure 1: Structure of KLEM production function

where

$$
M E_{(r)}=\left(\alpha_{(r)}^{\mathrm{Um}}\left(M_{(r)}^{\mathrm{total}}\right)^{\rho^{\mathrm{Ume}}}+\alpha_{(r)}^{\mathrm{Ue}}\left(E_{(r)}^{\mathrm{total}}\right)^{\rho^{\mathrm{Ume}}}\right)^{\frac{1}{\rho^{\mathrm{Ume}}}}
$$

and

$$
\begin{aligned}
T R N s_{(r)}^{\text {total }} & =T R N s_{(t ; r)}-\theta^{\mathrm{Utrns}} T R N s_{(t-1 ; r)}, \\
M_{(r)}^{\text {total }} & =M_{(t ; r)}-\theta^{\mathrm{Um}} M_{(t-1 ; r)}, \\
E_{(r)}^{\text {total }} & =E_{(t ; r)}-\theta^{\mathrm{Ue}} E_{(t-1 ; r)} .
\end{aligned}
$$

Thus, utility is a CES aggregate where non-transport material $M_{(t ; r)}$ and energy $E_{(t ; r)}$ are combined on the bottom level and transport services $T R N s_{(t ; r)}$ enters at the top level. Following the notation of the theoretical model presented before, $\alpha$ 's are input shares and $\theta$ 's determine the degree of habit persistence. Substitutability between different types of consumption is given by the different $\rho$ 's which relate to the respective substitution elasticity through $\sigma=\frac{1}{1+\rho}$. Figure 2 illustrates the utility function used in the general equilibrium analysis.

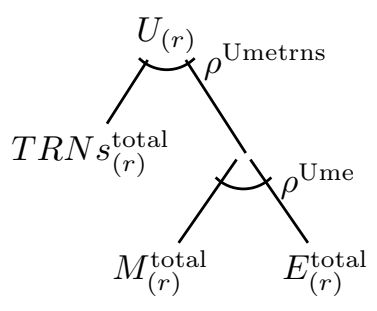

Figure 2: Structure of the utility function of households

Secondly, we include in the standard utility function a habit formation process similar to the one described in Section 2.1. If household have habits, they adjust only a share of their consumption bundle to the current situation and the other share is determined by their habits. Households must always consume at least $\theta^{\mathrm{Ue}} E_{(t-1 ; r)}$ of energy, $\theta^{\mathrm{Utrns}} T R N s_{(t-1 ; r)}$ of transport services, and $\theta^{\mathrm{Um}} M_{(t-1 ; r)}$ of non-transport material consumed in the previous period. Household habits are formed on the basis of the consumption bundle of the previous period and thus a change in a consumption decision will be quickly incorporated in household habits. The direct interdependence 
between current consumption and habits results in an adaptation process where current consumption and habits are adjusted period for period until a situation is reached where current consumption equals household habits. As was the case in the previous section, we therefore distinguish between a situation where the adaptation process has just started and habits have not been updated yet (here referred to as short-term) and a situation where the process is completed (here long-term) when illustrating the implications of consumption persistence.

Thirdly, we include a submodule describing the generation of transport services at the representative household $T R N s_{(t ; r)}$. We apply a similar formulation as Karplus (2011) and assume that households provide $T R N s_{(t ; r)}$ on the basis of a two-level nested CES production function of the form:

$$
\begin{aligned}
\operatorname{TRNs}_{(r)}= & \left(\alpha_{(r)}^{\mathrm{TRNpro}}\left(\operatorname{TRNpro}_{(r)}\right)^{\rho^{\mathrm{TRN} \text { propriv }}}\right. \\
& \left.+\alpha_{(r)}^{\mathrm{TRNpriv}}\left(\operatorname{TRNpriv}_{(r)}\right)^{\rho^{\mathrm{TRN} \text { propriv }}}\right)^{\frac{1}{\rho^{\mathrm{TRN} p r o p r i v}}}
\end{aligned}
$$

where

$$
\begin{aligned}
\operatorname{TRNpriv}_{(r)}= & \left(\alpha_{(r)}^{\mathrm{TRNe}}\left(\gamma_{(r)}^{\mathrm{TRNe}} E_{(r)}\right)^{\rho^{\mathrm{TRNma}}}\right. \\
& \left.+\alpha_{(r)}^{\mathrm{TRNma}}\left(T R N m a_{(r)}\right)^{\rho^{\mathrm{TRNetrnma}}}\right)^{\frac{1}{\rho^{\mathrm{TRN}} \operatorname{trnma}}}
\end{aligned}
$$

On the bottom level, energy $E_{(r)}$ used for private transport activities is paired with transport material $T R N m a_{(r)}$ to form private transport services $T R N p r i v_{(r)}$. On the top level, private transport services are combined with transportation services supplied by professionals, such as airlines or coach companies $T R N \operatorname{pro}_{(r)}$. Again, $\alpha$ 's are input shares and the degree of substitutability is given by the different $\rho$ 's. The level of energy efficiency is described by $\gamma_{(r)}^{\text {TRNe }}$, whereas in the benchmark $\gamma_{(r)}^{\text {TRNe }}$ is normalised to one. The overall structure of the production of transport services is given in Figure 3. Although again the nesting structure is slightly more complex, it nevertheless builds on the same concept as the illustrative example from the previous section.

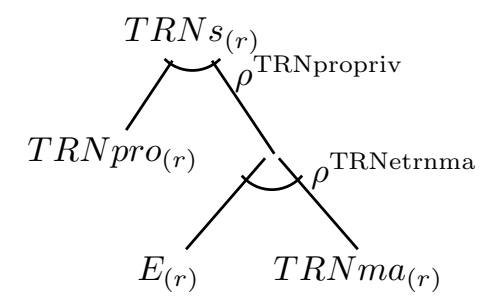

Figure 3: Structure of the provision of transport services

\subsection{Calibration, Aggregation, Key Parameters and Scenario Definition}

With regard to the general economic structure and energy use, the model is calibrated to 2009 WIOD data (Timmer et al. 2012, Dietzenbacher et al. 2013). Substitution 
elasticities for production are taken from Koesler \& Schymura (2012). We assume for the Armington elasticities of substitution between imports of different regions $\sigma^{\mathrm{MvsM}}$ and between the import aggregate and domestic products $\sigma^{\mathrm{LvsM}}$ that $\sigma^{\mathrm{MvsM}}=\sigma^{\mathrm{LvsM}}=5.1$

Originally, the WIOD dataset covers 40 regions and 35 sectors. But to be able to provide more pertinent, results we aggregate the extensive WIOD data to two regions and 19 sectors. Although our model includes the two regions Germany (GER) and Rest of the World (ROW), for our analysis, we focus on the effects within Germany and abstract from interregional effects. The setup of the sectoral aggregation has been chosen in particular such that it allows to explicitly model the provision of transport services to the households and to allow drawing conclusions regarding energy demand. This includes in particular the sectors providing professional transportation (ATRN, ITRN, WTRN), energy (ENER), and transport material (STRN, TREQ). A detailed overview of the regions and sectors is given in Tables 3 and 4 in the Appendix.

Besides having to know the share of household energy consumption relative to the economy-wide energy consumption for our analysis, we also require information on how much energy households use for private transport services. But while WIOD supplies detailed information on what type of energy households consume, it does not include information on the underlying purpose of household energy consumption. By making use of the facts that in Germany (bio-) diesel and (bio-) gasoline brought by households is used exclusively for transportation and that so far alternative propulsion technologies such as electric or gas powered cars are not wide-spread (cf. Kraftfahrt-Bundesamt 2011, 2012), we can derive the necessary information on the basis of the data reported in the energy use tables of WIOD. By these means, we conclude that household energy consumption accounts for $39.3 \%$ of total energy demand in Germany and households use $38.2 \%$ of this energy for the provision of private transport services which in turn corresponds to $15.0 \%$ of total German energy use.

With respect to our research question, there are a set of crucial parameters. These relate mainly to the degree of demand persistence respectively the strength of the habit, the substitution possibilities between transport services and non transport related consumption and the possibility to substitute energy with transport material in the generation of private transportation services. To account for sensitivity of the model results with regard to these key parameters, we run the simulations for a set of different scenarios. There are two main differences between scenarios. First, we distinguish between model runs with three different levels of demand persistence $\left(\theta_{\mathrm{NP}}=0, \theta_{\mathrm{MP}}=0.5\right.$ and $\left.\theta_{\mathrm{HP}}=0.9\right)$ to account for variation in degree by which households demand is driven by habits. Note that for this analysis, we focus on a case where household habits are homogenous for all services and consumer goods, i.e. $\theta^{\mathrm{Utrns}}=\theta^{\mathrm{Um}}=\theta^{\mathrm{Ue}}$. Secondly, to give an indication of the range of the implications of the efficiency shock in question, we

\footnotetext{
${ }^{1}$ To check for sensitivity with regard to Armington elasticities, we also match Armington elasticites from GTAP7 (Badri \& Walmsley 2008) to our dataset and evaluate the rebound. Albeit this requires a somewhat arbitrary match of WIOD sectors to GTAP7 sectors, there are no significant changes and our results seem to be robust to this regard.
} 
run a set of simulations with a ridged demand structure and an inflexible provision of private transport services. In this setting, we assume that households do not substitute between other consumer goods and transport services as well as between professional and private transportation $\left(\sigma_{\mathrm{MIN}}^{\text {Umetrns }}=0, \sigma_{\mathrm{MIN}}^{\mathrm{TRN} p r o p r i v}=0\right.$ and $\left.\sigma_{\mathrm{MIN}}^{\mathrm{TRNetrnma}}=0\right)$ and that energy and transport material cannot be substituted when providing private transport services $\left(\sigma_{\text {MIN }}^{\text {TRNema }}=0\right)$. These scenarios are supposed to provide us with rather conservative estimations of the effects. We also run a set of simulations with a more flexible demand structure. There, we assume that households adjust there consumption in such a way that the expenditure shares with regard to transportation services and other consumption and between private and professional transport services are constant $\left(\sigma_{\text {FLEX }}^{\text {Umetrns }}=1\right.$ and $\left.\sigma_{\text {FLEX }}^{\text {TRNopriv }}=1\right)$. Moreover, we assume that the generation of private transport services by households is characterised by a CES function featuring an elasticity of substitution of $\sigma_{\text {FLEX }}^{\text {TRNetrnma }}=0.42$. This value corresponds to the substitution elasticity between value added and energy for the sector providing inland transportation given in Koesler \& Schymura (2012). An overview of the scenarios is given in Table A in the Appendix of this paper.

\subsection{Simulation Results}

In the following, we present the simulation results regarding the economy-wide implications of a costless and permanent energy efficiency shock of $10 \%$ in the generation of private transport services by households in Germany. The efficiency improvement is applied by updating $\gamma_{\operatorname{scen}(G E R)}^{\mathrm{TRNe}}$ such that $\gamma_{\mathrm{scen}(G E R)}^{\mathrm{TRNe}}=1.1$. We begin with a situation where household demand features no persistence (NP-MIN and NP-FLEX). Later, we investigate how habits affect the results (MP-MIN, MP-FLEX, HP-MIN and HP-FLEX). Finally, in order to be able to pin down the magnitude of different rebound effects, we decompose the overall rebound observed in scenario NP-FLEX into the direct and indirect rebound effect.

\subsubsection{Implications without Habits}

A brief overview of the effects of the efficiency improvement in a setting without habits is given in Table 2. Naturally, the effects of the efficiency shock originate from the generation of transport services by households. As energy becomes more effective, input cost are reduced and the costs for one unit of transport services falls by $1.5 \%$ in the NP scenarios. Consequently, the demand of households for transport services and thus also its production increases by about $1.5 \%$ in the NP-FLEX scenario where household demand is flexible with regard to expenses for different consumption goods, but only increases slightly by $+0.1 \%$ in the less flexible NP-MIN scenario. As the demand for professional transport (air, inland and water) remains at its original level, any increase in transport demand can be attributed to an increased demand in private transportation services. Resulting from the increased provision of transport services, the demand for transport material (TREQ and $S T R N)$ and effective energy used for private transport 
should increase $2^{2}$ In fact, in scenario NP-FLEX, demand for transport material (TREQ and $S T R N$ ) increases slightly by $1.1 \%$ while the demand for energy increases by $5.3 \%$ in efficiency terms or decreases by $4.3 \%$ in natural units. Most of the change regarding energy inputs in the provision of private transport services can thereby be related to the the first and second term on the right hand side of Equation 7 from the stylised example presented in the previews section, meaning to changes in input intensity and current demand. Moreover, since the transport material intensity of transport services falls, at least a share of the energy increase must thereby be attributed to a change in input intensity. In deed, the divergent development of transport material and energy inputs in scenario NP-FLEX, where $0 \leq \sigma^{\text {TRNetrnma }} \leq 1$, can fully be attributed to the fact that households substitute transport material with comparatively cheap energy. Of course, as transport material and energy can not be substituted and the demand for transport remains unchanged, there is such rebound channel in in scenario NP-MIN and no change in intensities takes place.

Total household consumption increases only marginally by about $0.15 \%$ in NP-FLEX and about $0.14 \%$ in NP-MIN. As argued before, parts of this increase can be attributed to the fact that a reduction in prices for private transport services generates additional household demand. The other part can be related to the effect which was described in the stylised example by Equation 10. As households need to spend less on energy input, they can consume more. This includes energy as well as other goods and services. All this should in general have a positive effect on all sectoral outputs. In NP-FLEX and to a lesser extent in NP-MIN the sectors related to transport do indeed benefit from the additional demand for private transport services and expand their production by up to $0.61 \%$. However, the overall output of non-transport sectors does slightly decrease. The reason for this are general equilibrium effects and crowding-out. The additional demand by households and transport related sectors puts positive pressure on prices and increases input costs of all sectors. Sectors that cannot secure much extra demand must therefore limit their production. With a reduction of $0.69 \%$ in the NP-FLEX scenario and $1.42 \%$ in the NP-MIN case, the sector reducing its output most is the energy supplying sector ENER. Here the crowding-out is complemented by a drop in demand because of the energy efficiency improvement.

In terms of demand for energy (all measured in 'natural' units), we observe an economy-wide decrease of energy use in Germany of $0.8 \%$ in scenario NP-FLEX and of $1.6 \%$ in NP-MIN. German household demand for energy reduces by 1.7\% (NP-FLEX) and $3.4 \%$ (NP-MIN) respectively. Energy used for transportation decreases by $4.4 \%$ (NP-FLEX) and 9.0\% (NP-MIN). Since the possibilities to substitute towards energy are limited in the NP-MIN scenario, this once more illustrates that energy savings are eroded by an important share by substitution effects. The changes in energy use leads

\footnotetext{
${ }^{2}$ Note, in the context of changes in efficiency it is necessary to distinguish between 'natural' and 'efficiency' units. For example, assuming all other things remain unchanged, a $10 \%$ efficiency increase of an input will result in a $10 \%$ decrease of the input usage measured in 'natural' units, but input usage in 'efficiency' units will remain constant.
} 
us to the main point of interest, the rebound effect. Building on the work of Lecca et al. (2013), we measure rebound on the basis of the relationship between changes in the use of energy measured in 'natural' units and the relative size of the efficiency increase:

$$
R_{s}=\left(1+\frac{\Delta E_{s}}{\left(\frac{E_{u}}{E_{s}}\right) \Delta \gamma}\right) 100 \%
$$

This rebound measure includes direct, indirect as well as economy-wide effects. In a general equilibrium setting which simultaneously incorporates different supply- and demand side processes, rebound can be evaluated for different scopes or perspectives. In Equation (16) $s$ is the scope and $u$ the activity where the efficiency change takes place. Accordingly, $E_{s}$ respectively $E_{u}$ is energy use, $\Delta E_{s}$ is the change in energy use within the scope $s$ (all three are measured in 'natural' units) and $\Delta \gamma$ is the change in efficiency taking place in activity $u$. In this analysis, we consider three scopes and compute the rebound for the provision of transport services $R_{T R N S}$, household consumption $R_{C}$ and the economy as a whole $R_{E}$. Figure 4 summarises our results regarding the rebound effect if household consumption is not influenced by habits. If households are flexible with regard to their preferred consumption bundle (NP-FLEX), $56.2 \%$ of the energy efficiency improvement in the provision of transport services is lost because of rebound. Because of the absence of substitution effects when households are less flexible, the loss is much lower and amounts only to $10.4 \%$ in the NP-MIN scenario. The rebound on the level of total household consumption is $56.2 \%$ in the NP-FLEX scenario and again reduces to $12.6 \%$ in the NP-MIN scenario. The increase of the rebound effect when changing from a transport service perspective to a more comprehensive household perspective can be explained by the additional energy consumption by households thanks to lower costs for the provision of transport services when these services become more energy efficient. Broadening the scope of the rebound to an economy-wide perspective, results in a rebound of $48.5 \%$ (NP-FLEX) and $-4.5 \%$ (NP-MIN) respectively. When taking a more comprehensive perspective, the energy savings from the energy efficiency improvement are reinforced by the reduction of sectoral output in particular in energy intensive sectors such as ENER, ATRN, ONME and META. As a consequence rebound is reduced. This is in line with the findings of Lecca et al. (2013) who postulate that the rebound effect on the economy level should be smaller than the rebound on the household level if total energy consumption decreases. As a matter of fact, in scenario NP-MIN, the total German energy demand decreases so strong that we can report a negative rebound effect. Thus, in this special case, the usually counterproductive rebound channels eventually generate an additional benefit.

\subsubsection{Implications in the Presence of Habits}

As previously illustrated formally, consumer habits can have an initial negative effect on rebound triggered from an energy efficiency improvement. Table 2 also provides an overview of key effects of a $10 \%$ energy efficiency increase in the provision of private 




Figure 4: Rebound if household consumption is not influenced by habits

transportation in the presence of consumer habits. If households feature a rigid demand structure with regard to substitution between different goods (MP-MIN, HP-MIN), there is no difference between a situation with or without habits. The reason for this is straightforward. If households do not change the nature of their demand, there is no need to update the consumption bundle they are already used to, and thus there is no effect of habits.

If households are ready to substitute but are bound by habits (MP-FLEX, HPFLEX), household energy demand for the provision of transportation services initially declines by 5.0\% (MP-FLEX) and 5.6\% (HP-FLEX), respectively. Total household energy demand reduces by 1.9\% (MP-FLEX) and 2.1\% (HP-FLEX), while economy-wide energy use decreases by only $0.9 \%$ (MP-FLEX) and 1.0\% (HP-FLEX). Again, all changes are measured in 'natural' units. Compared to a situation without habits (NP-FLEX) there is thus a stronger decline of energy use at each level. The effect is stronger the higher the persistency level $\theta$. As the provision of transport services itself is not constraint by habits, and thus input substitution can still take place, the increased decline can be attributed to the comparatively limited change in demand for transport services. In the presence of habits, households refrain from taking advantage of the cost decrease the efficiency improvement implies and demand for transport services does only rise by $0.8 \%$ (MP-FLEX) and 0.3\% (HP-FLEX) compared to an increase of $1.5 \%$ in a situation where habits are no issue (NP-FLEX). This also implies that the general equilibrium effects through which other sectors where affected by the efficiency shock are now also 
weakened. Output in the transport material sectors for example is now only expanded by up to $0.2 \%$ in comparison to $0.6 \%$ in the NP-FLEX scenario. An exception is the energy sector ENER, which reduces its output more strongly by $0.8 \%$ (MP-FLEX) respectively $0.9 \%$ (HP-FLEX). This is mainly because additional demand for transport services is constrained by habits.

In terms of rebound, this results in the predicted initial reduction of the rebound effect for scenario MP-FLEX and HP-FLEX compared to NP-FLEX. Rebound at the transport service level amounts to $49.7 \%$ (MP-FLEX) respectively $44.5 \%$ (HP-FLEX), at the household level to $50.8 \%$ (MP-FLEX) and $41.0 \%$ (HP-FLEX) and $34.9 \%$ (MPFLEX) respectively $46.5 \%$ (HP-FLEX) at the economy-wide level. Again the differences of between the rebound for different scopes can be explained by additional household energy demand and negative effects on the output of non-transport sectors. But the effect of habits on the rebound is limited to the short run. In the long run, when households have had the chance to truly update their consumption bundle to the new situation, energy demand and correspondingly the rebound effect would have returned to those values emerging from a situation without consumption persistence (NP-FLEX). The effect of habit is only permanent if household consumption is fully determined by habits. Obviously, in such a situation households would never react to the efficiency improvement with a change of their consumption bundle.

\subsubsection{Decomposing the Rebound}

In order to shed more light on the strength of different rebound channels, we disentangle the rebound observed in scenario NP-FLEX into the direct and indirect rebound effect. Thereby, we build on the respective definitions elaborated in the section presenting the stylised model of the previous section which are formalised in Equations 6 and 10 . In the process, we use numerical approximations of the required partial derivatives and for parameterisation turn to the same data we use in the CGE model. It must be noted however, that this approach relies on a ceteris paribus analysis and only holds at the margin. As a consequence, the direct and indirect rebound are isolated effects and are not additive in forming an overall demand side effect. Thus $R^{\text {Total }} \equiv R^{\text {Direct }}+R^{\text {Indirect }}+$ $R^{\text {Equilibrium }}$ does not apply in this setup.

In a situation without consumer habits and where household demand is flexible with regard to expenses for different consumption goods (NP-FLEX), the direct rebound of a $10 \%$ increase of energy efficiency in the provision of private transport in Germany amounts to $64.7 \%$. This implies that in isolation, the direct rebound effect would erode a large part of the energy efficiency shock. At first, such a high estimate for the direct rebound seems to be at odds with other estimates that can be found in the literature, which, according to a comprehensive review by Sorrell et al. (2009), range from $10 \%$ to $30 \%$. But considering that, in particular in Germany and in the context of transportation, the direct rebound appears to be higher and amounts to something around $60 \%$ (Frondel et al. 2008, 2012), our estimate nevertheless seems plausible. 


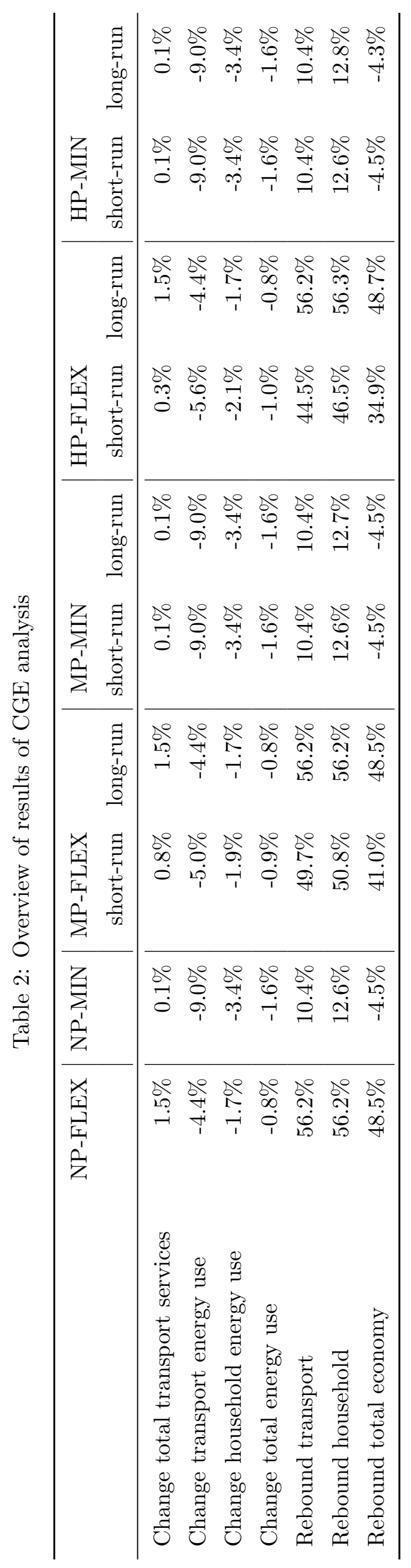


Based on our definition as outlined in 10 , the indirect rebound resulting from a $10 \%$ efficiency increase of transport energy in Germany is 19.9\% in the NP-FLEX scenario. So while the indirect rebound does reduce the expected savings of an energy efficiency measure, in isolation, this channel is weaker than the price effect leading to direct rebound. To our humble knowledge, there exist only few estimates of the indirect rebound and often the underlying definition varies. The lack of estimates makes it difficult to contrast our finding with the literature. The only study we found that matches roughly our definition is Sorrell (2007), who reports an indirect rebound of $11 \%$. This estimate is clearly smaller than ours, but still it seems to be within range.

\section{Summary and Conclusion}

In this paper, we turn our attention to the rebound effect of an efficiency improvement at households and investigate the implications of an efficiency change in the provision of private services by households. In the process, we take into account that household behaviour may be influenced by habits and build on a detailed representation of the provision of private transport services. To have a clear understanding of the underlying effects, we first formally illustrate through which channels the rebound effect emerges on the basis of a simple stylised example. Subsequently, we evaluate the effects of a $10 \%$ energy efficiency improvement in the provision of private transport services by German households by means of a more comprehensive CGE analyis.

Our analysis shows that rebound has the potential to significantly reduce the expected energy savings of an energy efficiency improvement at households. Particularly if households have a flexible demand structure, rebound can erode large parts of efficiency increases and in our setting rebound amounts to up to $56 \%$. Household habits have an initial detrimental effect on rebound. They limit the ability of households to adapt to changes in the prevailing price and income system and therewith temporally block parts of the channels that lead to rebound. In the long run however, if habits are formed on the basis of historic consumption and household behaviour is not totaly driven by habits, they do not affect rebound. In isolation and on the basis of a ceteris paribus analysis, the direct rebound effect of the 10\% efficiency improvement can amount up to $64.7 \%$ and the indirect rebound to $19.9 \%$.

On the basis of our study, we cannot aline ourself with the statement of Gillingham et al. (2013) that the rebound is overplayed. On the contrary, in the context of energy efficiency improvements in households, rebound is crucial. Although, in our study, we concentrate on an ad-hoc efficiency improvement, this is also an important finding for policy makers. Efficiency improvements are often believed to be vital to achieve sustainability and policy makers are frequently tempted to prescribe energy efficiency improvements by regulatory law (e.g. EU 2009). But when discussing such measures, policy makers should be fully aware of the associated rebound potential. This is not to say that compulsory efficiency improvements can not be beneficial, but the rebound 
effect puts the effectiveness of such measures to a real test. The results of our study point also to another aspect of the rebound that policy makers should take into account. In the presence of consumer habits, rebound can take some time until its full extent manifests itself. Consequently, an evaluation of energy efficiency measures should always allow for sufficient amount of time so that households can adopt their behaviour to the new situation. The longer habits take to be formed, the longer the time span should be that passes before the rebound effect can be assessed properly. Otherwise, the rebound effect will be underestimated. 


\section{References}

Acemoglu, D. (2002), 'Directed technical change', Review of Economic Studies 69(4), 781-809.

Alexeeva-Talebi, V., Böhringer, C., Löschel, A. \& Voigt, S. (2012), 'The value-added of sectoral disaggregation: Implications on competitive consequences of climate change policies', Energy Economics 34, Supplement 2(0), S127-S142.

Armington, P. S. (1969), A theory of demand for products distinguished by place of production, Technical report, International Monetary Fund, Washington, USA.

Badri, N. G. \& Walmsley, T. L. (2008), Global Trade, Assistance, and Production: The GTAP 7 Data Base, Technical report, Center for Global Trade Analysis, Purdue University, West Lafayette, USA.

Berkhout, P. H. G., Muskens, J. C. \& Velthuijsen, J. W. (2000), 'Defining the rebound effect', Energy Policy 28(6-7), 425-432.

Dietzenbacher, E., Los, B., Stehrer, R., Timmer, M. \& de Vries, G. (2013), 'The construction of world input-output tables in the WIOD project', Economic Systems Research 25(1), 71-98.

EU (2009), Regulation (EC) No 443/2009 of the European Parliament and the of the Council of 23 April 2009 setting emission performance standards for new passenger cars as part of the Community's integrated approach to reduce $\mathrm{CO} 2$ emissions from light-duty vehicles, Technical report, European Union, Brussels, Belgium.

Frondel, M., Peters, J. \& Vance, C. (2008), 'Identifying the rebound: Evidence from a German household panel', The Energy Journal 29(4), 145-163.

Frondel, M., Ritter, N. \& Vance, C. (2012), 'Heterogeneity in the rebound effect: Further evidence for Germany', Energy Economics 34(2), 461-467.

Frondel, M. \& Vance, C. (2013), 'Rebound effect is not an exaggeration', Nature 494(7434), 430.

Gillingham, K., Kotchen, M. J., Rapson, D. S. \& Wagner, G. (2013), 'Energy policy: The rebound effect is overplayed', Nature 493(7433), 475-476.

Karplus, V. J. (2011), Climate and Energy Policy for U.S. Passenger Vehicles: A Technology-Rich Economic Modeling and Policy Analysis, PhD thesis, Massachusetts Institute of Technology, Cambridge, USA.

Koesler, S. \& Schymura, M. (2012), Substitution elasticities in a CES production framework: An empirical analysis on the basis of non-linear least squares estimations, Technical report, Zentrum für Europäische Wirtschaftsforschung (ZEW), Mannheim, Germany. 
Kraftfahrt-Bundesamt (2011), Fachartikel: Emissionen und Kraftstoffe, Technical report, Kraftfahrt Bundesamt, Flensburg, Germany.

Kraftfahrt-Bundesamt (2012), Fahrzeugzulassungen (FZ) - Bestand an Kraftfahrzeugen nach Emissionen und Kraftstoffen, Technical report, Kraftfahrt Bundesamt, Flensburg, Germany.

Lecca, P., McGregor, P. G., Swales, K. \& Turner, K. (2013), The added value from a general equilibrium analyses of increased efficiency in household energy use, Technical report, University of Strathclyde Business School, Department of Economics, Glasgow, United Kingdom.

Pollak, R. A. (1970), 'Habit formation and dynamic demand functions', Journal of Political Economy 78(4), 745-763.

Schipper, L. J. (2000), 'On the rebound: The interaction of energy efficiency, energy use and economic activity. an introduction.', Energy Policy 28(6-7), 351-353.

Sorrell, S. (2007), The Rebound Effect: An assessment of the evidence for economy-wide energy savings from improved energy efficiency, Technical report, UK Energy Research Centre, London, United Kingdom.

Sorrell, S. \& Dimitropoulos, J. (2008), 'The rebound effect: Microeconomic definitions, limitations and extensions', Ecological Economics 65(3), 636-649.

Sorrell, S., Dimitropoulos, J. \& Sommerville, M. (2009), 'Empirical estimates of the direct rebound effect: A review', Energy Policy 37(4), 1356-1371.

Timmer, M. P., Erumban, A. A., Gouma, R., Los, B., Temurshoev, U., de Vries, G. J., Arto, I., Andreoni, V., Genty, A., Neuwahl, F., Rueda-Cantuche, J. M. \& Villanueva, A. (2012), The World Input-Output Database (WIOD): Contents, sources and methods, Technical report, available at http://www.wiod.org/database/index.htm, Groningen, The Netherlands.

Turner, K. (2013), 'Rebound effects from increased energy efficiency: A time to pause and reflect', The Energy Journal 34(4), 25-42.

van den Bergh, J. (2011), 'Energy conservation more effective with rebound policy', Environmental and Resource Economics 48(1), 43-58.

von Weizsäcker, C. C. (1971), 'Notes on endogenous change of tastes', Journal of Economic Theory $\mathbf{3}(4)$, 345-372. 


\section{A Appendix}

Table 3: List of regions

\begin{tabular}{lll}
\hline Short & Regions & Associated WIOD Regions \\
\hline GER & Germany & DEU \\
ROW & Rest of the World & AUT, BEL, BGR, CYP, CZE, DNK, ESP, EST, FIN, \\
& & FRA, GBR, GRC, HUN, IRL, ITA, LTU, LUX, LVA, \\
& MLT, NLD, POL, PRT, ROM, SVK, SVN, SWE, AUS, \\
& BRA, CAN, CHN, IDN, IND, JPN, KOR, MEX, ROW, \\
& RUS, TUR, TWN, USA \\
\hline
\end{tabular}

Table 4: List of sectors

\begin{tabular}{lll}
\hline Short & Sectors & Associated WIOD Sectors \\
\hline AGWO & Agriculture and Wood & AtB, 20 \\
ATRN & Air Transport & 62 \\
CHEM & Chemicals and Plastics & 24,25 \\
CONS & Construction & $\mathrm{F}$ \\
ELEQ & Eletrical Equipment & $30 \mathrm{t} 33$ \\
ENER & Energy & $\mathrm{C}, 23, \mathrm{E}$ \\
FOOD & Food, Beverages, Tobacco & $15 \mathrm{t} 16$ \\
ITRN & Inland Transport & 60 \\
MACH & Machinery & 29 \\
MANU & Manufacturing & $36 \mathrm{t} 37$ \\
META & Metal & $27 \mathrm{t} 28$ \\
ONME & Other Non-metallic Minerals & 26 \\
PAPE & Paper & $21 \mathrm{t} 22$ \\
SERV & Services & $51,52, \mathrm{H}, 63,64, \mathrm{~J}, 70,71 \mathrm{t} 74$, \\
& & $\mathrm{L}, \mathrm{M}, \mathrm{N}, \mathrm{O}, \mathrm{P}$ \\
STRN & Services for Private Transport Equipment & 50 \\
TEXT & Textiles and Leather & $17 \mathrm{t} 18,19$ \\
TREQ & Transport Equipment & $34 \mathrm{t} 35$ \\
WTRN & Water Transport & 61 \\
\hline
\end{tabular}


Table 5: Overview of scenarios

\begin{tabular}{llllll}
\hline Short & Scenario & $\begin{array}{l}\text { Habit } \\
\theta\end{array}$ & $\begin{array}{l}\text { Substitution } \\
\sigma^{\text {Umetrns }}\end{array}$ & $\sigma^{\text {TRNpropriv }}$ & $\sigma^{\text {TRNetrnma }}$ \\
\hline NP-MIN & $\begin{array}{l}\text { no persistence } \\
\text { inflexible consumption }\end{array}$ & 0.00 & 0.00 & 0.00 & 0.00 \\
MP-MIN & $\begin{array}{l}\text { medium persistence } \\
\text { inflexible consumption }\end{array}$ & 0.50 & 0.00 & 0.00 & 0.00 \\
HP-MIN & $\begin{array}{l}\text { high persistence } \\
\text { inflexible consumption }\end{array}$ & 0.90 & 0.00 & 0.00 & 0.00 \\
NP-FLEX & $\begin{array}{l}\text { no persistence } \\
\text { flexible consumption } \\
\text { medium persistence }\end{array}$ & 0.00 & 1.00 & 1.00 & 0.42 \\
MP-FLEX & $\begin{array}{l}\text { flexible consumption } \\
\text { high persistence }\end{array}$ & 0.90 & 1.00 & 1.00 & 0.42 \\
HP-FLEX & flexible consumption & & & 1.00 & 0.42 \\
\hline
\end{tabular}

